\title{
Individual differences in working memory strategies for reading expository text
}

\author{
DESIREE BUDD, PAUL WHITNEY, and KANDI JO TURLEY \\ Washington State University, Pullman, Washington
}

\begin{abstract}
This study investigated whether individual differences in working memory (WM) span are associated with different WM management strategies during the reading of expository text. In Experiment 1 , probe questions were presented on line during reading to determine whether thematic information was maintained in WM throughout comprehension. The data indicated that readers across the range of WM span maintained thematic information in WM throughout the reading of a given passage. In Experiment 2, sentence reading times and accuracy for both topic and detail questions were measured in two conditions: when topic sentences were present and when topic sentences were absent. Subjects performed similarly across the range of WM span in the topic-present condition, but lower span subjects performed more poorly on detail questions in the topic-absent condition. In Experiment 3 , the topic-present condition of the second experiment was replicated, except that subjects expected to receive questions about details only. Thematic processing and retention of topic and detail information all increased with span. Taken together, these results suggest that, for more difficult text processing tasks, high- and low-span subjects adopt different WM management strategies and these strategies influence what is learned from reading the text.
\end{abstract}

There is growing evidence that individual differences in working memory (WM) capacity have profound influences on the process of text comprehension. It has been known for some time that measures of WM capacity that assess storage and processing limitations are highly correlated with performance on tests of reading ability (see, e.g., Baddeley, Logie, Nimmo-Smith, \& Brereton, 1985; Daneman \& Carpenter, 1980). Most evidence for this correlation comes from tests of WM similar to Daneman and Carpenter's reading span task. In this task, subjects must process a series of sentences while holding the final word of each sentence in their memory. However, exploring the relationship between WM capacity and reading holds promise not only for our understanding of individual differences in reading ability, but also for a greater understanding of both the general characteristics of working memory, and the normative process of comprehension.

For example, Engle and colleagues (Engle, Cantor, \& Carullo, 1992; Turner \& Engle, 1989) have shown that WM span tasks correlate with reading ability because they tap a general-purpose capacity for maintaining verbal information. Turner and Engle (1989) showed that

This research was supported by AFOSR Grant F49620-92-J-0243. The first two experiments were part of a master's thesis submitted to Washington State University by D.B. We thank Mike Donnelly for his help in the preparation of this manuscript. We would also like to thank Bill Ritchie for his help in writing the stimulus passages and collecting the initial pilot data. Portions of these data were presented at the meeting of the Psychonomic Society. Address correspondence to P. Whitney, Department of Psychology, Washington State University, Pullman, WA 99164-4820 (e-mail: whitney@wsuvml.csc.wsu.edu). the correlation between working memory and reading ability remains high even if the WM span task does not involve reading at all. In addition, Engle et al. (1992) ruled out the hypotheses that the WM-reading-ability correlation exists only because more intelligent subjects simply use better strategies on both WM and reading tests. Thus, there is evidence that there exists a general WM capacity that is used in a wide range of cognitive tasks (see Baddeley, 1986).

Of particular interest to the present research is the recent evidence that individual differences in WM span are associated with qualitative differences in comprehension processes (see, e.g., Just \& Carpenter, 1992; Lee-Sammons \& Whitney, 1991; Perfetti, 1985; Whitney, Ritchie, \& Clark, 1991). Just, Carpenter, and colleagues (Just \& Carpenter, 1992; MacDonald, Just, \& Carpenter, 1992) found that readers who scored high on the WM span task (high spans) differed from readers who scored low (low spans) on a number of measures. For example, high-span readers were better able to maintain two possible interpretations of a syntactic ambiguity. In addition, high-span readers, unlike low-span readers, were able to use semantic information (animacy of a noun) to facilitate syntactic processing of relative clauses. The latter result, in particular, exemplifies how research on individual differences in WM can have an impact on normative theories of comprehension. If the syntactic processor is really an informationally encapsulated part of the cognitive architecture (Fodor, 1983), use of semantic information to facilitate syntactic processing should not be associated with WM span (Just \& Carpenter, 1992).

High-span and low-span readers also display qualitative differences in text-level comprehension processes. 
For example, Whitney et al. (1991) investigated whether WM span is related to the type of inferences made when subjects read difficult, ambiguous prose. Subjects were asked to "think out loud" about their interpretation of each passage as they read it. Low-span readers made more concrete interpretations of the text. Low-span readers also made their elaborations early in the text, whereas elaboration by high-span readers occurred later in the text. Whitney et al. concluded that the low-span readers made their interpretations early because they did not have the capacity to wait until they had enough information to draw appropriate inferences.

Lee-Sammons and Whitney (1991) examined the effect of WM span and reading goals on comprehension of narrative text. Subjects read a story about two boys skipping school. The subjects read either from the perspective of a potential home buyer or from the perspective of a potential burglar and later recalled the text either from the encoding perspective or from the perspective not given at encoding. Low-span readers were poor at recalling information not relevant to the original encoding perspective, even when cued with the alternative perspective. High-span readers recalled similar amounts of perspective-relevant and perspective-irrelevant information, regardless of cuing. Lee-Sammons and Whitney (1991) concluded that the degree to which subjects used the goal to guide their comprehension processes varied inversely with WM span.

Although previous research supports the conclusion that readers with different WM spans use qualitatively different WM management strategies to guide their comprehension processes (Just \& Carpenter, 1992; LeeSammons \& Whitney, 1991; Whitney et al., 1991), these findings have been largely obtained by using narrative texts as stimuli. Little research has been done to determine whether these WM span differences are present for expository materials.

One of the reasons that it is important to extend this research to expository text is that the study of the various WM management strategies used by readers to comprehend expository text can be applied to the problem of how to improve learning from text. If the adoption of particular strategies results in specific tradeoffs in text comprehension processes, this is likely to lead to differences in what material is learned while one is reading an exposition. For example, several studies indicate that readers who use a thematic, or structural, strategy to comprehend text recall more top-level information than do readers who process text in a linear, element-by-element fashion (Loman \& Mayer, 1983; Marshall \& Glock, 1979; Meyer, Brandt, \& Bluth, 1980; Meyer \& Rice, 1982; Reder \& Anderson, 1980). Thus, if we understand the tradeoffs that some readers make to comprehend expository text, we might be able to manipulate reader strategies or text characteristics to enhance learning efficiency.

In a more theoretical vein, the study of the comprehension of expository text is a natural means of exploring WM management. As Fletcher (1986) noted, the structure of expository text is far more variable and thus less pre- dictable than that of narrative text (Black, 1985; Britton, Glynn, \& Smith, 1985; Fletcher, 1986). In addition to its less uniform structure, expository text often contains novel terms that are difficult to understand without specific background knowledge. The reader's lack of prior knowledge about the particular situation represented by an expository text, as well as the novel concepts associated with it, may place greater cognitive demands on the reader than those usually associated with narrative text (Kieras, 1982, 1985). These demands may result in the adoption of management strategies for processing expository text that differ from those used to process narrative text.

The purpose of the present study was twofold. First, we wanted to determine whether similar emphasis was placed on thematic processing by readers with different WM spans. A central tenet of recent models of reading comprehension is the idea that working memory plays a dual role in the establishment of coherence between various parts of a text (e.g., Fischer \& Glanzer, 1986; Kieras, 1982; Kintsch, 1988; Kintsch \& van Dijk, 1978; Sanford \& Garrod, 1981). According to these models, readers maintain the most recently processed information from the text in WM in order to establish relations between adjacent clauses or sentences. Thus, WM plays a role in facilitating the comprehension of specific propositions by establishing coherence at a local level. However, texts are also coherent at a more global, or thematic, level. Thus, most models of reading comprehension claim that topic information is maintained in WM to promote thematic processing (Glanzer \& Nolan, 1986; Just \& Carpenter, 1987; Kieras, 1982; Kintsch \& van Dijk, 1978). In some circumstances, readers may not have the processing capacity to buffer both thematic and local information in WM. As a simple example, consider a low-span reader who has difficulty extracting proposition-specific information while at the same time maintaining thematic information in WM. Such a reader might forgo maintaining thematic information in order to process particular details fully. Alternatively, the reader might perform shallow processing of the details in order to focus on the overall theme of the passage. In the Lee-Sammons and Whitney (1991) study, the low-span readers apparently traded local processing of perspective-irrelevant information for more extensive processing of information relevant to the thematic perspective.

Second, we wanted to establish whether use of particular WM management strategies affects the type of information that is learned while reading expositions. Several theorists have suggested that when readers' WM resources are severely limited, assembly and integration of propositions in WM are constrained, and the quality of the text representation suffers (Johnson-Laird, 1983; Just \& Carpenter, 1987; Kintsch et al., 1993; Perfetti, 1989; van Djik \& Kintsch, 1983). Accordingly, individual differences in WM capacity may be related to differences in what information is retained when one is reading expositions.

To somewhat simplify the study of WM management processes, we used passages with a two-level hierarchi- 
cal structure. Each passage began with a topic sentence that stated a general proposition. This sentence was followed by several detail sentences, each of which independently supported the topic sentence. Because topic sentences generally occur in the initial position of expository passages, readers consider information mentioned first as more thematically important than information mentioned later, and therefore as especially important to the overall representation of the text (Kieras, 1982, 1985; Lorch, Lorch, \& Matthews, 1985; Meyer, 1975; van Dijk \& Kintsch, 1983). Kieras (1985) and others (Hare, Rabinowitz, \& Schieble, 1989) have suggested that when one is reading passages with this simple hierarchical structure, thematic processing involves mostly recognizing that the pattern of details support some general concept. If the general concept is stated at the beginning of the passage, readers need only adopt it, and then test it for adequacy against the remainder of the passage. However, if an obvious candidate for the topic does not occur first, readers must construct one while reading, test it for adequacy, and be prepared to modify it if new information arises that does not support the readers' initial interpretation (Hare et al., 1989; Kieras, 1982; Smith \& Swinney, 1992).

More specifically, this simple two-level hierarchical structure allowed us to distinguish different WM management strategies by restricting the nature of the relational processing performed by readers. In general, relational processing involves the integration or organization of the individual propositions within a text (Einstein, McDaniel, Owen, \& Cote, 1990). Of course, integration can take place at a local level between adjacent sentences as well as at a more thematic level. Because the detail sentences described facts that were independent of each other except for their support of the theme of the passage, we could expect that most of the relational processing would be thematic and involve relating each detail sentence to the topic (Hare et al., 1989; Kieras, 1985).

Given the nature of the passages used in this research, there were three types of processes that our subjects could employ to retain information from the passages. They could perform item-specific processing of the topic sentences, which would help them retain the theme of a passage. They could perform item-specific processing of details, which is necessary to encode any particular detail. Finally, they could perform relational processing in which the specific detail information was related to the theme of the passage. According to Einstein et al. (1990), retention of information should be best when readers perform extensive item-specific processing in conjunction with extensive relational processing. Thus, relational processing performed by subjects in the present experiments was expected to aid retention of both topic and detail information.

Of course, our main interest was in whether the relative emphasis on each of these three types of processes varied with WM capacity. On the basis of the earlier research with narrative texts (e.g., Lee-Sammons \& Whitney, 1991), we predicted that low-span subjects, unlike high-span subjects, would face tradeoffs between performing extensive item-specific and extensive relational processing. In the Lee-Sammons and Whitney study, the type of tradeoff that low-span readers should make was evident because perspectives were given to guide comprehension. However, in Experiments 1 and 2, we emphasized retention of topic and detail information equally, so that we could determine the direction that processing tradeoffs take when the experimental task does not suggest a particular direction to the tradeoff. In Experiment 3 , we emphasized the importance of detail information, to determine how high- and low-span readers would adapt their comprehension processes to fit the type of questions they expected to be asked.

Each of the experiments in this study followed the same general plan, though Experiment 1 was based on a probe technique and Experiments 2 and 3 focused on sentence reading times. For each experiment, we first examined the data from all subjects collectively to see whether we had replicated prior research. We then tested whether the group results were qualified by an interaction with WM span. Most research in this area has tested for such interactions by arbitrarily creating high-, medium-, and low-span groups and conducting an analysis of variance (ANOVA). Although the data analysis then becomes very familiar, this artificial creation of groups often results in a substantial sacrifice in power (Cronbach \& Snow, 1977; Pedhazur, 1982). Rather than conduct an ANOVA based on an arbitrary grouping of the WM span range, we tested the significance of the regression weight that represented the interaction between WM span and the categorical independent variables in each experiment. Thus, the continuous nature of the WM span variable was maintained, which not only increased power, but also allowed us to better examine the range of WM span scores that are associated with differences in performance.

\section{EXPERIMENT 1}

In an attempt to discover what type of information was being carried in WM during the reading of expository text, Glanzer and Nolan (1986) measured subjects' response times to true/false probe questions about specific topic and detail information contained in brief expository passages. Subjects read passages organized in the same hierarchical fashion as the passages in this study. The subjects' response times to the questions were used to determine whether topic and detail information was maintained in WM. When the probe questions were presented immediately following the related sentence, subjects answered both topic and detail probe questions quickly. However, when the probe questions were presented after three intervening sentences, response times to the detail probe questions increased and response times to the topic probe questions did not change. Glanzer and Nolan concluded that topic information was given a privileged role and carried longer in WM than detail information. 
In Experiment 1, we used a probe deadline methodology that was modified from Glanzer and Nolan's (1986) study to assess whether WM capacity was related to the tendency to maintain thematic information in WM. For instance, Glanzer and Nolan's results might be correct normatively, but inaccurate for lower span readers who might find it impossible to process each detail sentence fully while also maintaining thematic information in WM. Such readers would perform mainly item-specific processing, with little emphasis on relational processing. Alternatively, because relating the detail information to a general theme can benefit the retention of detail information (see Reder \& Anderson, 1980; Risko \& Alvarez, 1986), maintaining thematic information might be worth the WM "cost" to low-span readers, and they might maintain thematic information just as higher span readers do.

In the present study, the subjects answered true and false probe questions about specific topic and detail information while they read the passages. Originally, we intended to use reaction time to the probe questions as the dependent measure (cf. Glanzer \& Nolan, 1986). However, a pilot study indicated that several subjects were trading speed for accuracy when given unlimited time to respond. Therefore, a probe deadline procedure was used. On the basis of pretesting of the materials with a separate group of low- and high-span subjects, we allowed subjects in the main experiment $3.5 \mathrm{sec}$ to respond to the probe. Among pretested subjects, when the probe immediately followed the relevant sentence, both highand low-span subjects could read and respond to the probe within the deadline with $70 \%-80 \%$ accuracy. Consequently, mean proportion correct was our dependent measure in Experiment 1. The probe questions were presented immediately after the relevant sentence (lag 0 ), after two intervening sentences (lag 2), or after four intervening sentences (lag 4). We predicted that collapsed over WM spans, the accuracy data would replicate the results of Glanzer and Nolan. That is, accuracy for topic probe questions would be constant across lag, and accuracy for detail probe questions would decrease with lag. More importantly, if thematic relational processing varies as a function of WM capacity, the size of the lag effect for topic probes should vary with WM span.

\section{Method}

\section{Subjects}

The subjects were 96 undergraduate students from Washington State University who participated either for extra course credit or to fulfill a general psychology course requirement. All subjects were native speakers of English. All subjects completed two sessions. In the first session, subjects were given the WM span test, as described below. Each subject then returned on another day to complete the reading task. The WM span scores for this sample of subjects ranged from 15 to 55 (the maximum possible score is 60 ). The mean WM span score was 36.5 , with a standard deviation of 9.8 .

\section{WM Span Test}

Materials. The WM span test was adapted from one developed by Turner and Engle (1989). The materials consisted of response booklets for each subject and 15 overhead transparencies containing sets of unrelated sentences. There were 60 sentences in all, rang- ing from 10 to 16 words in length, each ending in a noun. Half of the sentences used active voice (e.g., "The group of fans walked to the baseball game, slipping and sliding on the icy surface.'), and half were passive (e.g., "The wife was looked after by her adoring husband to make sure she received no harm."). Fifteen "nonsense" sentences were created from each of the two structure types by scrambling the last 4-6 words immediately preceding the final word. The number of sentences per transparency ranged from 2 to 6 . There were three transparencies for each of the set sizes. Following the last sentence on each transparency was the phrase "RECALL wORDS." Each response booklet contained 30 pages, with 2 pages corresponding to each transparency. The Ist page in the set was constructed so that the subject could indicate whether each sentence in the set made sense or not. The 2 nd page was blank except for the phrase "RECALL WORDS."

Procedure. The sentences were presented in order of increasing set sizes on an overhead projector. Individual sentences were presented at a rate of one every $7 \mathrm{sec}$. As each sentence was presented, the subject judged whether or not it made sense. After rating each sentence in a set, subjects turned to the next page in their booklets and tried to recall the last word of each sentence in the set. Subjects were credited with recalling a word only if the subject had also made a correct sense judgment for the corresponding sentence.

\section{Reading Comprehension Task}

Materials and Design. Twenty-four passages were adapted from articles in various nontechnical science and hobby magazines. Each passage was organized in a simple hierarchical structure consisting of a topic sentence (a generalization of what the passage was about) and six supporting detail sentences. Three probe questions and one multiple-choice question were constructed for each passage. One probe question was constructed for the topic sentence and one probe question was constructed for the first or second detail sentence after the topic sentence. The last probe question, which was a filler probe, was constructed for another detail sentence selected at random from the passage. Each passage ended in the filler probe so that subjects could not determine any pattern in the test probes. Probe questions were constructed to be paraphrases of explicit information contained in the related sentence and were between 12 and 14 words in length. Half of the probes of each type were true and half were false. The multiple-choice questions for the passages were constructed so that half the multiple-choice questions tested topic information and half tested detail information. A sample passage and probe questions are given in Table 1.

Six versions of each passage were created by crossing probe type (topic vs. detail) and lag (zero, two, or four intervening sentences). Six versions of the experiment were also created so that each contained a unique version of each passage, and each condition (probe type $\times$ lag) occurred equally often. Subjects were randomly assigned to versions.

Procedure. Subjects were given the reading comprehension task individually in sessions lasting between 40 and $60 \mathrm{~min}$. The instructions and the passages were presented on personal computers with VGA monitors. The experiment was programmed with the MEL software system. A sentence-by-sentence, self-paced procedure was used. Subjects were given general instructions on how to control text presentation, and they performed one practice block of six passages to familiarize them with the procedure and orient them to the type of questions that would be asked. Each trial began with a one- or two-word title that appeared on the screen (e.g., "Oil Spill"). The subject then initiated the presentation of the first sentence of the passage by pressing the space bar. After reading a sentence, the subject initiated the next sentence by pressing the space bar again. The subject continued in this manner until an entire passage was read.

Subjects were informed that they were going to read passages dealing with various topics, and that they should read each passage 
Table 1

Sample Text of Passage With Topic and Detail Probe Questions

In a race to save animals after the Exxon Valdez oil spill, the problems of the clean-up workers were often overlooked.

$\mathrm{T}-0$

During the first few weeks after the Exxon Valdez oil spill, clean-up workers received only an hour of training.

D-0

Protective clothing was often unavailable for the clean-up workers.

T-2

Clean-up workers worked for days at a stretch in the same oil-soaked clothes.

D-2

One reason for concern is that the highly toxic components in the oil take days to evaporate.

T-4

Necropsies on dead otters revealed severe emphysema-presumably from breathing the fumes from the freshly spilled oil.

D-4

No one knows for sure what types of serious long term health problems the clean-up workers might face.

Topic probe question: The problems of the clean-up workers were usually overlooked.

Detail probe question: Most of the clean-up workers received many hours of training.

Note-T-0, T-2, T-4, D-0, D-2, D-4 indicate the locations of the topic probe questions (T) and detail probe questions (D) at each of the distances.

carefully in preparation for a test at the end of each block of six passages. They were also informed that true/false probe questions would appear at random intervals while they were reading, and that these probes were to help them determine how well they were reading the passage. Text sentences were left justified in black letters on a gray background: probe questions appeared in white letters on a blue background. Subjects were told that they would have only $3.5 \mathrm{sec}$ to read and respond to the probe, and that if they did not re spond within the time limit, the response would be counted as incorrect. If the subject answered correctly within the time limit, then "Correct Response" appeared on the screen. If they responded incorrectly or failed to respond within the time limit, then "Incorrect Response" appeared on the screen in conjunction with a tone.

After every six passages, the computer displayed a set of multiplechoice questions pertaining to the six preceding passages. The questions appeared on the screen one at a time, and the subjects answered them by pressing the number key on the keyboard that corresponded to the best answer. However, because of a programming error, data from the multiple-choice questions were not collected properly, so these data could not be analyzed.

\section{Results and Discussion}

In analyzing the probe data, we had to remove any subjects who performed at chance levels at lag 0 , because such floor effects would make the paradigm insensitive to lag effects. Accordingly, 24 subjects were replaced for failure to obtain a mean percentage correct above $50 \%$ at lag 0 for combined topic and detail probe questions. Five of the subjects who were replaced had relatively high span scores (above 46), while 8 of the replaced subjects were low in span (below 27). The rest of the replaced subjects scored within one standard deviation of the mean span score.

The mean proportions of correct responses to topic and detail probe questions by lag $(0,2,4)$ are given in Table 2. To see whether we had replicated Glanzer and Nolan's results, we first tested for lag effects in both topic and detail probes in a set of analyses parallel to theirs - that is, without removing variability due to individual differences in WM span. An alpha level of .05 was used for all significance tests.

Despite using different materials and a probe deadline procedure rather than reaction time, we replicated the earlier results. The small decrease in performance on topic probes over lag was not significant $[F(2,190)=$ $\left.2.03, M S_{\mathrm{e}}=.050, p>.10\right]$. There were significant lag effects for detail probes $\left[F(2,190)=12.23, M S_{\mathrm{e}}=.047\right]$.

Overall, the same pattern was obtained across the range of WM span scores. Figures 1 and 2 show the performance on the probe questions plotted over WM span for topic and detail probes, respectively. The bin width used to plot the effects over WM span was chosen by starting with the lowest WM span score in the sample and selecting divisions that would ensure that each mean represented at least 12 subjects. As Figure 1 suggests, there was a general increase in performance on topic probes with WM $\operatorname{span}\left[F(1,94)=16.97, M S_{\mathrm{e}}=.037\right]$. More importantly, there was no lag effect and no WM span $\times$ lag interaction (both $F \mathrm{~s}<1$ ). In contrast, there was a significant lag effect for detail probes $[F(2,188)=$ $\left.5.39, M S_{\mathrm{e}}=.247\right]$. The main effect of WM span on answers to detail probes was marginal $[F(1,94)=3.10$, $\left.M S_{\mathrm{e}}=.051, p=.08\right]$.

Although Figure 2 shows that lag effects were consistently obtained over the whole WM span range, we did obtain a WM span $\times$ lag interaction for detail probes $\left[F(2,188)=3.09, M S_{\mathrm{e}}=.046\right]$. This interaction apparently resulted from an anomaly at the lowest WM span levels. For the lowest span subjects, the performance at lag 4 is considerably better than the performance at lag 2 . The reason for this effect is unclear. It could represent some sort of end-of-passage rehearsal strategy to prepare for the late probe question, or it could be a spurious result. If the improvement in performance at lag 4 should turn out to be a reliable effect that interacted with WM span, it would certainly be worthy of further study. However, for now, our main interest was in whether WM span would interact with performance on the topic probes, and clearly it did not.

Table 2

Mean Proportion of Correct Responses as a Function of Lag: Experiment 1

\begin{tabular}{ccccc} 
& \multicolumn{3}{c}{ Lag } & \\
Probe Type & 0 & 2 & 4 & $M$ \\
\hline Topic & .80 & .75 & .74 & .05 \\
Detail & .84 & .69 & .73 & .13 \\
\hline
\end{tabular}

Note- $M$, mean of net lag effect for lag 2 and lag 4 . 
The major result of Experiment 1 is that regardless of WM span level, readers maintained topic information across sentences to a greater degree than they maintained detail information. Thus, the first experiment established that low-span readers were not limiting topic maintenance in order to process details. If lower span readers were making such a tradeoff, we should have observed lag effects for topic probes at the lower levels of WM span. We found no such evidence, though the data from the detail probes clearly show we had sufficient power to detect both lag effects and interactions between WM span and lag. However, a possible objection to Experiment 1 is that the paradigm used was invasive and interrupted subjects' normal reading behavior. Thus, the data might not reflect normal reading processes. Also, because we had to replace several subjects in the first experiment because of poor performance on the probe task at lag 0 , it could be argued that the lowest span subjects used in Experiment 1 were not representative of low-span readers in general. Therefore, in Experiment 2, a noninvasive reading time measure was used to assess differences in WM management strategies.

Another purpose of Experiment 2 was to present the subjects with a somewhat more demanding reading task. Several researchers have found that when processing demands are minimal, there are fewer differences between the performances of high- and low-span subjects (Just \& Carpenter, 1992; Raney, 1993). For example, Raney found that reaction time on a secondary task (tone detection) was similar for both high- and low-span readers when subjects read short, simple passages. However, when the text was longer and more difficult, and the total number of responses a reader was required to make on the secondary task was increased, the reaction times on the secondary task were longer for low-span readers than

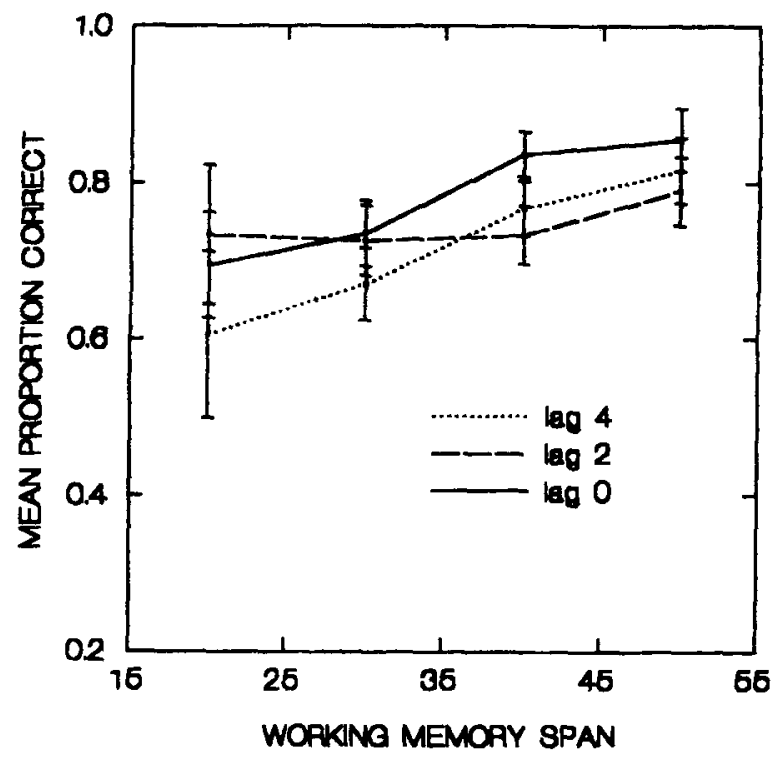

Figure 1. Means (and standard error bars) for performance on topic probe questions as a function of working memory span in Experiment 1.

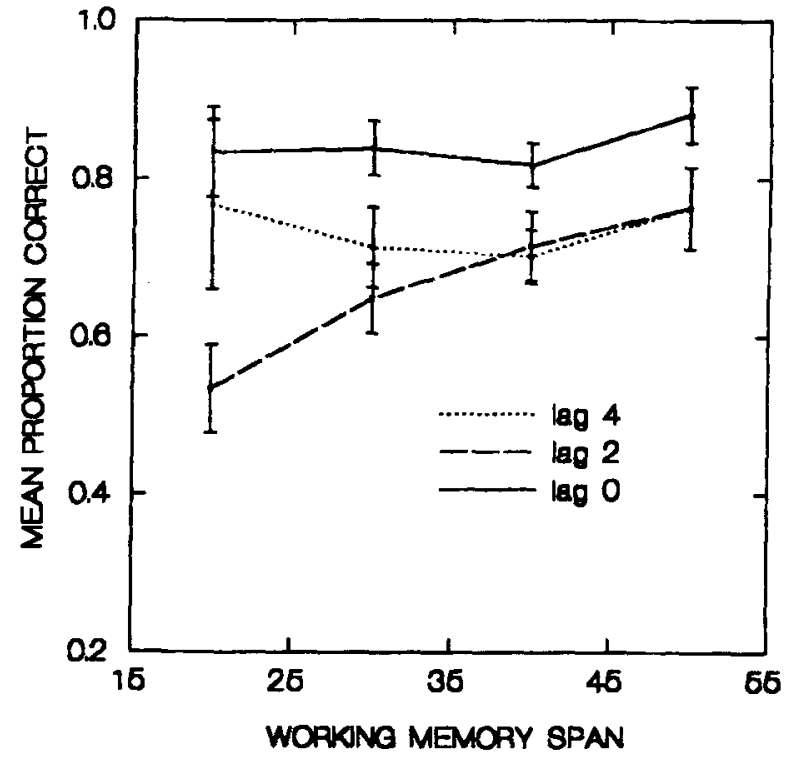

Figure 2. Means (and standard error bars) for performance on detail probe questions as a function of working memory span in Experiment 1.

for high-span readers. Raney concluded that the processing demands associated with the shorter, easier passages did not exceed the resources of the low-span subjects. Accordingly, in Experiment 2, we tested whether lower span readers would continue to perform thematic processing even when that processing was made more difficult by having subjects read some passages without topic sentences.

\section{EXPERIMENT 2}

A wide range of studies has shown that readers typically assume that the first sentence of an expository passage is of special thematic importance. Initial sentences are rated higher in importance (see, e.g., Kieras, 1984) and they are usually remembered better than sentences at other serial positions (Kieras, 1981b; Meyer, 1975). A series of studies by Kieras (1981 a, 1981b, 1982) showed that sentence position effects are also observed in reading times. For example, Kieras (1982) found longer reading times for topic sentences than for detail sentences with simple expository passages. Kieras (1982) also found that if the topic sentence was deleted so that the initial detail sentence now appeared first, subjects read this detail sentence much longer than they did when it occurred as the second sentence of the passage.

Kieras (1982) attributed the longer reading time to the thematic processing that occurs because the first sentence is taken as the topic sentence. The effect of initial position was particularly pronounced in the condition in which the true topic sentence was deleted, perhaps because readers experienced greater difficulty in constructing a topic when one was not explicitly stated in the sentence. Support for this interpretation came from stud- 
ies (Kieras, 1984) in which reading times for initial sentences were consistently under predicted by a set of variables (e.g., length, number of new arguments, parsing difficulty) that predicted reading times for other sentences very well. Thus, the first sentence of a passage is processed longer than would be expected from its other properties. In the model developed by Kieras (1982), this additional processing time was taken as an index of thematic processing. Depending on the reading context, the additional time taken to process the first sentence can vary from approximately $500 \mathrm{msec}$ to more than a second (cf. Kieras, 1981a, 1984).

If readers perform relational thematic processing, we would expect that increased reading times would not be limited to the first sentence of a passage. Several studies have shown that the first several sentences of a passage are read longer than later sentences. For example, Haberlandt and Graesser (1985) reported just such a serial position effect on sentence reading times, and this effect remained significant even when differences in the number of new arguments among the sentences was partialed out. Likewise, Olson, Mack, and Duffy (1981) found longer reading times for the first three to four sentences of wellstructured passages. In a parallel "thinking out loud" experiment, it was shown that subjects were performing more thematic processing in these early sentencesdrawing topical inferences and making predictions. These data are consistent with a model of comprehension in which readers establish a theme as early as possible and relate this theme to new information as more sentences are read (e.g., Kintsch \& van Dijk, 1978). With successive sentences, this integration process becomes easier as the thematic representation is refined and has a richer set of propositions to relate to new information (Haberlandt, 1984; Haberlandt \& Graesser, 1985).

In the present experiment, we adapted the reading time paradigm used by Kieras (1982) in order to examine whether amount of thematic processing is associated with variations in WM span. Subjects read modified versions of the passages from Experiment 1. Half the passages were presented without a topic sentence. Reading times for the identical sentences in the topic-absent and topic-present conditions were collected and compared. Subjects were also required to answer one multiplechoice question about each passage. Half the multiplechoice questions were about topic information and half were about detail information. Unlike the task used by Kieras (1982), in which comprehension was tested by having the subjects state the main idea of the passage, the comprehension task used in this study emphasized retention of both thematic and detail information. Thus, if a tradeoff became necessary, the direction of tradeoff was not dictated by the comprehension task, but, instead, the direction was left to the subject. If high- and low-span subjects use WM management strategies that utilize similar thematic processing, as suggested by the data from Experiment 1, then all subjects should take more time to read the first sentence in the passage than to read subsequent sentences in both topic-absent and topic-present conditions. Also, accuracy for topic questions should not vary by span. If the thematic processing carried out by low-span subjects in the topic-absent condition takes place at the expense of proposition-specific processing of detail information, then low-span subjects would answer less detail questions correctly than high spans in the topic-absent condition. Of course, as noted earlier, an emphasis on thematic processing may aid retention of details, but only if two conditions are met: the reader must possess adequate resources to also perform adequate proposition-specific processing of detail information, and the thematic processing must be relationalthe theme and the detail must be associated in memory (cf. Einstein et al., 1990).

\section{Method}

\section{Subjects}

Seventy-two undergraduates from Washington State Lniversity participated for extra course credit or to fulfill a general psychology course requirement. All subjects were native speakers of English. Subjects were administered the WM span test used in Experiment 1 . The sample of subjects obtained was very similar to that of the first experiment. The WM span scores ranged from 15 to 53 , with a mean of 35.5 and a standard deviation of 9.3 .

\section{Materials and Design}

The 24 passages from Experiment 1 were modified for use in Experiment 2. The topic sentence and the first detail sentence of each passage were altered so that mean reading times for each type of sentences in isolation were equated. Therefore, reading time differences between the first sentence in the topic-present condition and the first sentence in the topic-absent conditions could be attributed to sentence position effects and not to any differences in sentence length or difficulty. A pilot study done with 26 subjects indicated that mean reading times for these new topic and detail sentences were $9,086 \mathrm{msec}(S E M=230)$ and $9,242 \mathrm{msec}(S E M=$ 185 ), respectively. All other sentences in each passage were the same as those used in Experiment 1. Additionally, a topic-absent and topic-present version of each passage was created.

Two multiple-choice questions were also const ructed for each passage. Each question was constructed so that subjects had three alternatives from which to choose. One question asked about explicit detail information, and one question asked about topic information. The detail questions were constructed so that they would require knowledge of the specific information contained in the related detail sentence (e.g., "How many hours of training did most of the clean-up workers receive?"). The topic questions could be answered either directly from the information contained in the topic sentences or by using the detail sentences to infer the correct response. For example, the topic question for the passage in Table 1 was as follows:

\footnotetext{
After the Exxon oil spill, the problems of the clean-up workers:

1. were given high priority and often put ahead of the needs of the wildlife endangered by the oil spill.

2. were low priority and often put behind the needs of the wildlife endangered by the oil spill.

3. were not given top priority, but were usually taken care of in a timely manner.
}

The independent variables of passage type and question type were manipulated within subjects. Four versions of the experiment were created. Each version contained six trials of each passage type (topic present, topic absent) by question type (topic. detail) condition. Across versions, every passage appeared in each condition. Subjects were randomly assigned to versions at the begimning of the experiment. 


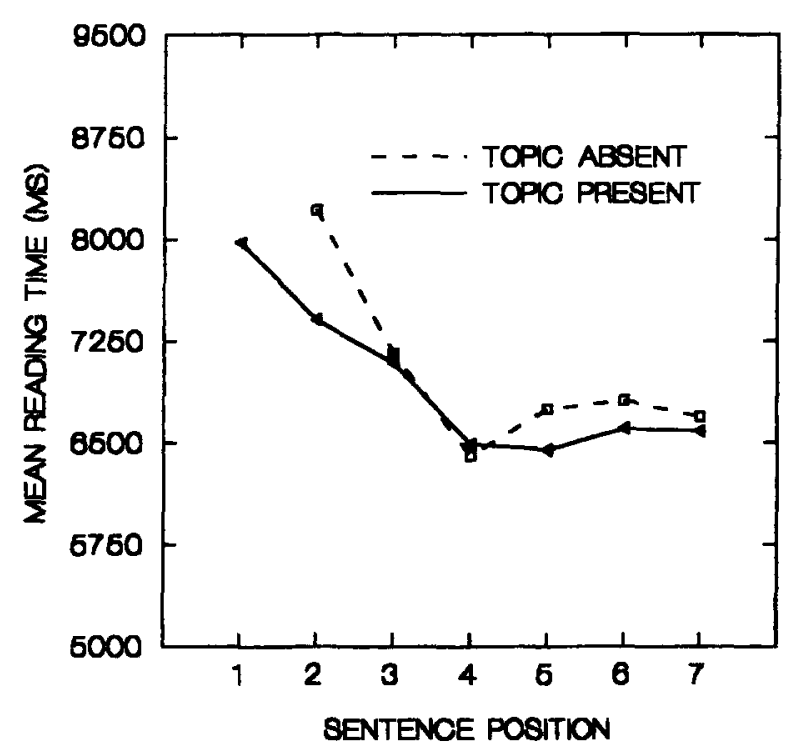

Figure 3. Reading times by sentence position for group data in Experiment 2. Standard errors of the means ranged from approximately 140 to 170 msec.

\section{Procedure}

The subjects were given the WM span test in one session and returned on a later day to complete the reading comprehension task. The reading comprehension session lasted $40-60 \mathrm{~min}$. The presentation of the passages was the same as in Experiment 1, except that there were no probe questions. Subjects were given general instructions on how to control text presentation, and they performed one practice block of six passages to familiarize them with the procedure and orient them to the type of questions that would be asked.

Subjects were informed that they were going to read passages dealing with various topics of interest, and that they should read each passage carefully in preparation for a test at the end of each block of six passages. After every six passages, the computer displayed a set of multiple-choice questions pertaining to the six preceding passages. Questions were displayed one at a time, and there was one question per passage. Half the questions were about detail information and half were about topic information. The computer recorded the subject's response to each question and gave the subject feedback regarding accuracy.

\section{Results and Discussion}

Eight subjects (from various span levels) were replaced because their poor performance on the multiplechoice questions suggested that they were not reading carefully. All the other subjects scored above $50 \%$ correct on combined topic and detail questions. We will present the reading time data first; then we will discuss the subjects' responses on the comprehension questions.

\section{Reading Times}

The analyses were performed on the mean reading times for each subject in each condition. Reading times for individual trials that were greater than $14,000 \mathrm{msec}$ and less than $2,000 \mathrm{msec}$ were eliminated from the analysis. Approximately $2 \%$ of the observations were eliminated. Figure 3 shows mean reading times in both the topic-absent and topic-present conditions over sentence position.

The data from the subjects taken as a group clearly replicate other data on sentence position effects (see, e.g., Kieras, 1985). The decline in reading time with sentence position is significant both in the topic-present condition $\left[F(6,426)=30.92, M S_{\mathrm{e}}=674,351\right]$ and in the topic-absent condition $\left[F(5,355)=49.26, M S_{\mathrm{e}}=\right.$ $601,908]$. As predicted by Kieras (1982), reading time for the first detail sentence was longer in the topicabsent condition than in the topic-present condition $\left[F(1,71)=45.25, M S_{\mathrm{e}}=517,493\right]$.

To determine whether there was converging evidence for our conclusion that all subjects were performing thematic processing in Experiment 1, we needed to derive an index of thematic processing from the reading time data. On the basis of the data in Figure 3, it appeared that reading times declined and then leveled off at Sentence Position 4. We checked the passages to see whether this drop could be explained simply in terms of sentence lengths. However, the average number of syllables in the topic sentence was only 2.75 more than the average number of syllables in Sentence $4(S D$ difference $=12.62)$. This difference did not approach significance in a repeated measures $t$ test $(p>.20)$. This suggested that we could take the average decline in reading time up to Sentence 4 as an index of thematic processing. This procedure would remove most of the effects of factors other than thematic processing, particularly since all the detail sentences described independent supporting evidence for the theme and the more unfamiliar technical terms found in these passages occurred almost invariably among the detail sentences. Thus, even those sentences presented later in the passages included considerable

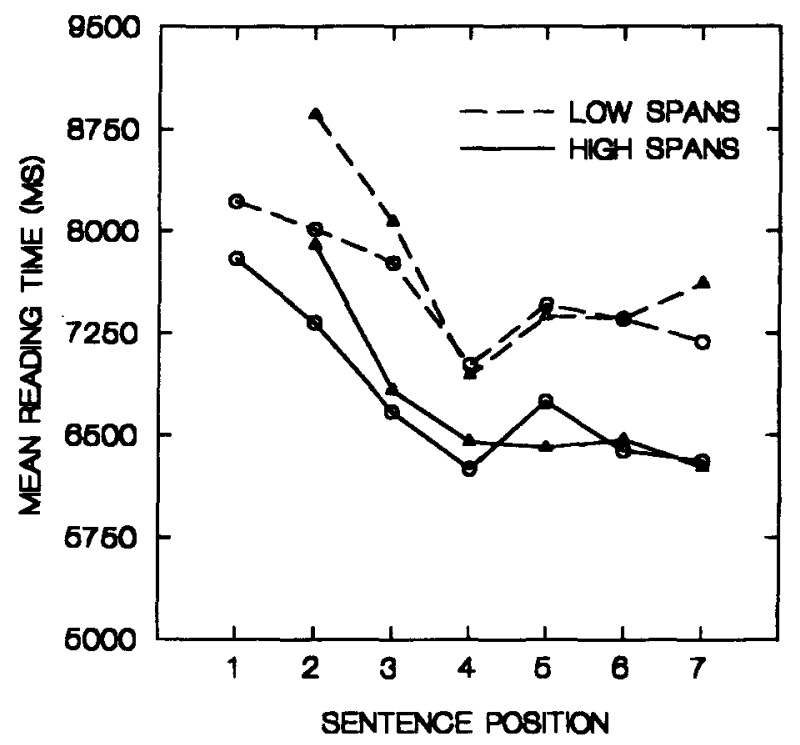

Figure 4. Reading times by sentence position for subjects at the highest and lowest third of working memory span scores in Experiment 2. Circles denote the topic-present condition, and triangles denote the topic-absent condition. 
new detail information, but no new thematic information. However, before calculating this index of thematic processing for each subject, we checked the assumption that the function in Figure 3 was representative of the reading time function across various levels of WM span. In Figure 4, the reading time data are displayed separately for groups formed from the upper and lower tertiles of span scores. Trend analyses on each of the functions displayed in Figure 4 showed a linear decline in reading time over Sentence Positions 1-3, and a quadratic trend when Sentence Position 4 was added to the analyses

Given that the general form of the serial position function was similar at each end of the continuum of WM span scores, we calculated, for each subject, the average decline in performance over Sentence Positions 1-4 in the topic-present condition and Positions $2-4$ in the topicabsent condition. Figure 5 shows this index of thematic processing plotted over span for both the topic-present and the topic-absent conditions.

Consistent with the data from the first experiment, neither the topic-present nor the topic-absent data varied with WM span (both $F \mathrm{~S}<1$ ). Again, we found evidence that thematic processing was used similarly by subjects across the range of WM capacity. We should also note that the values in Figure 5 (approximately 500 $1,000 \mathrm{msec}$ ) fall closely in line with the estimates of thematic processing times obtained by Kieras (1981a, $1981 \mathrm{~b}, 1982,1985)$ under similar conditions. We also found that reading times were longer in the topic-absent condition, in which the subject must infer the theme from the details $[t(71)=4.53]$, a finding that further supports our contention that this index taps into thematic processing.

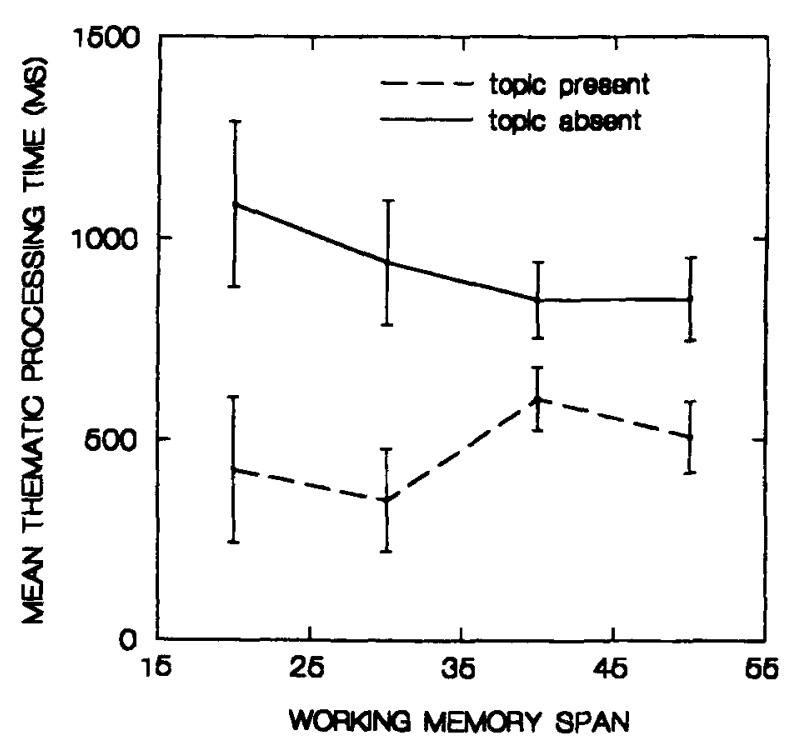

Figure 5. Relation between thematic processing and working memory span in Experiment 2 for both the topic-present and topicabsent conditions.

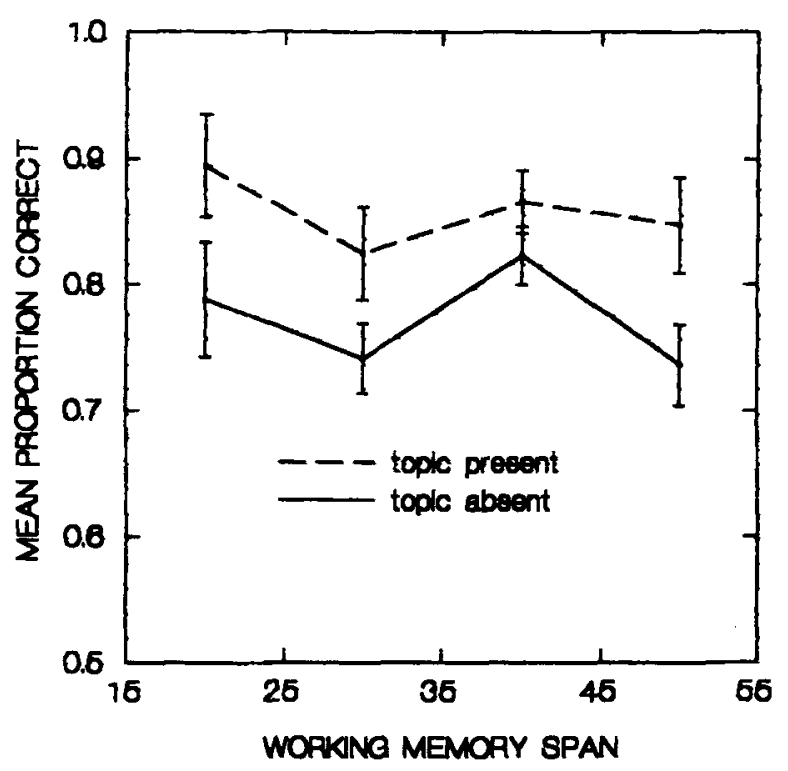

Figure 6. Performance on topic comprehension questions in Experiment 2.

\section{Comprehension Questions}

Because the reading time data indicated that the amount of thematic processing did not vary with WM span, we did not expect to see a relation between answers to topic questions and WM span. The data shown in Figure 6 confirmed this expectation. There was no general effect of WM span on answers to the topic questions $(F<1)$, nor did WM span interact with the topicabsent versus topic-present condition $(F<1)$. Although there was a trend toward lower overall performance in the topic-absent condition ( $M=.78$ for topic absent and $M=.85$ for topic present), the main effect of this variable was not significant $(p>.20)$.

The more interesting question with regard to the comprehension questions was whether thematic processing engendered any cost or benefits to retention of details at some levels of span. The relevant data are shown in Figure 7. For the answers to the detail questions, there was a significant interaction between the topic condition and WM span $\left[F(1,70)=5.72, M S_{\mathrm{e}}=.022\right]$. Only at the very low end of WM capacity did performance suffer in the topic-absent condition. Increasing the difficulty of thematic processing by deleting the explicit topic sentence, does not appear to influence performance on the detail questions unless WM capacity is quite low.

There are two important findings from Experiment 2. First, the reading time data support the conclusion from Experiment 1 that subjects across the WM span range performed thematic processing. Second, when thematic processing was made somewhat more difficult by leaving the topic unstated, there was a concomitant decrease in performance on detail questions for subjects who were lowest in WM capacity. For these low-span readers, the difficulty of constructing the theme in the topic-absent condition may have decreased the item-specific process- 


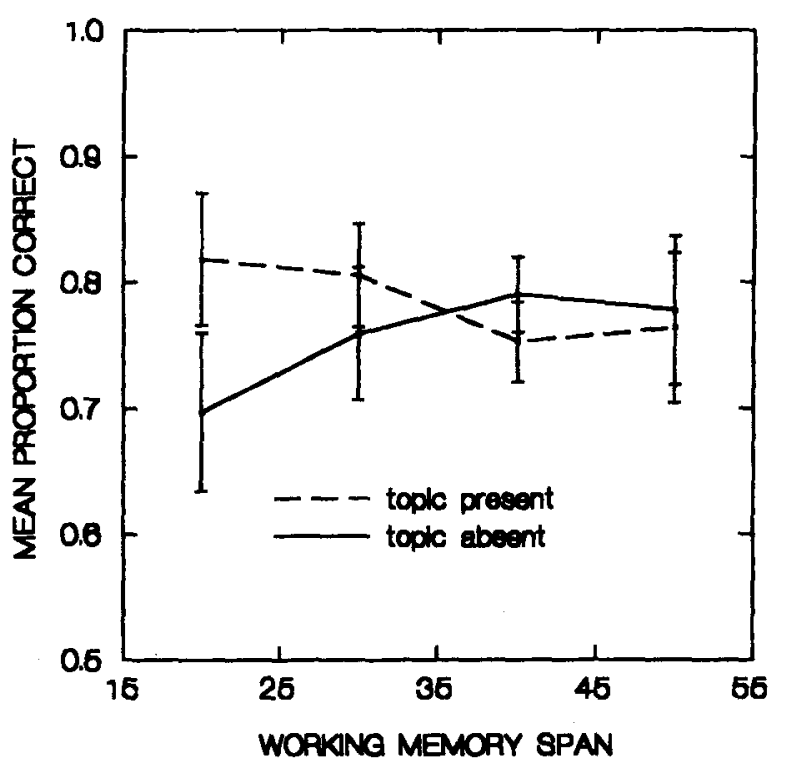

Figure 7. Performance on detail comprehension questions in Experiment 2.

ing of details, which, in turn, would have decreased their ability to perform relational processing between the theme and the details. These findings raise questions about what conditions foster differences in WM management strategies as a function of processing capacity. Throughout the first two experiments, subjects with different WM capacities appeared to be using a similar WM management strategy in terms of their relative emphasis on the processing of thematic information. The only difference obtained thus far was in the consequences of thematic processing for comprehension of particular details. However, in both experiments, subjects were asked questions that explicitly required knowledge of the topics of the passages. Thus, it might be argued that the similarity in thematic processing we have seen across different span levels was due to the explicit demands of the comprehension questions. We explored this issue in the third experiment.

\section{EXPERIMENT 3}

For Experiment 3, we replicated the topic-present condition of Experiment 2, except that no questions about the topics of the passages were asked until a surprise test at the end of the experiment. Thus, we were interested in whether subjects would alter their thematic processing when they had no reason to expect questions about anything other than specific details. However, it is unclear whether most readers can alter their reading strategies to fit the type of comprehension test they receive (cf. Epstein, Glenberg, \& Bradley, 1984). The data from Experiment 2 suggest that for readers with higher WM capacity, increased thematic processing does not lower performance on questions about specific details. In fact, if retention of specific details is emphasized, a reason- able strategy for the higher span readers would be to use relational thematic processing to assist in retention of detail information (cf. Einstein et al., 1990).

\section{Method}

\section{Subjects}

We obtained 120 subjects from the same subject population used for the previous experiments. The WM span scores for this sample ranged from 15 to 55 , with a mean of 34.7 and a standard deviation of 8.4 .

\section{Materials and Design}

The topic-present versions of the 24 passages from Experiment 2 were used in the present experiment. The topic and detail multiplechoice questions from Experiment 2 were used as a surprise additional test of comprehension at the end of the study. In place of asking the multiple-choice questions at the end of each block of six passages, we created true/false probe questions to follow the reading of each passage. These questions were used to orient the reader toward an emphasis on retention of details. Two true/false probes were created for each passage. Half the probes were true, and half were false.

\section{Procedure}

The passages were presented in the same manner as in Experiment 2. The practice block of trials included the same type of true/false detail probes as in the rest of this study. After each passage, a probe question was presented in white letters on a blue background (sentences were presented in black letters on a light gray background). Subjects were given 5 sec to respond to each probe, and the computer provided feedback regarding accuracy. Subjects were told that their task was to read each passage carefully so that they could answer questions that would occur at the end of each passage. They were not told about the multiple-choice questions that they were asked to answer once they had finished reading all the passages. After a subject had completed all the trials, two blocks of multiple-choice questions were presented one block of detail questions and one block of topic questions. The order of the blocks was counterbalanced across subjects. Each de-

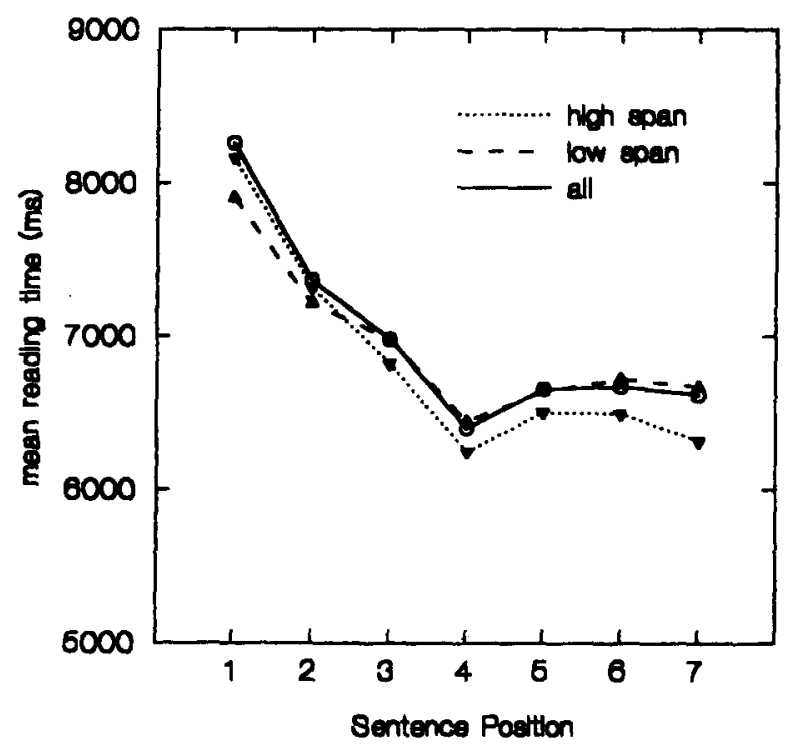

Figure 8. Reading times by sentence position for subjects at the upper and lower quartile of working memory span scones in Experiment 3. 
tail question asked about information different from that tested by the corresponding probe question for a given passage. Each block consisted of 24 questions, one question for each passage. Subjects were told that this surprise test was to further evaluate their memory for the text that they had just read.

\section{Results and Discussion}

The treatment of the data for this experiment follows that of the second experiment. The same outlier criteria were used for the reading time data, and we performed the analyses first on the group data to check for replication of previous results before we explored the individual differences. In addition, we performed the analyses of both the reading time and question answering data separately over the counterbalancing variable - that is, for the 60 subjects who received the detail questions first and for the 60 subjects who received the topic questions first at the end of the experiment. The pattern of results was the same for each group, so all the analyses reported here are based on the full sample of 120 subjects.

\section{Reading Times}

The general pattern of reading times as a function of sentence position was closely in line with the data from Experiment 2. Figure 8 shows the data for the full sample and for the upper and lower quartiles of the WM span distribution. Obviously, the decline in reading times for the whole sample data is significant $[F(6,714)=249.4$, $\left.M S_{\mathrm{e}}=197,864\right]$. Although the low-span subjects have a shallower function, it is clear that the general pattern is the same as for the whole sample, and the same as for Experiment 2.

On the basis of the similarity of the functions in Figure 8 with each other, and with the data from Experiment 2, we calculated the index of thematic processing for each subject in the same manner as in the previous experiment. These data are shown as a function of WM span in Figure 9. The data are strikingly different from those of the previous experiment. Rather than the consistent thematic processing across WM span found in the previous experiment, there was a significant increase in thematic processing with increases in level of WM span $\left[F(1,118)=9.24, M S_{\mathrm{e}}=59,320\right]$. Comparison of the thematic processing times with those obtained in the second experiment makes it clear that the difference between the two studies occurs in the behavior of higher span readers. At lower levels of WM span, the subjects performed very similarly to the subjects in Experiment 2 . However, when retention of details was emphasized in Experiment 3, the higher span readers responded with an increase in thematic processing in comparison with subjects in the earlier study, and in comparison with the lower span readers in the same condition. With orienting questions that increased the salience of the importance of retaining detail information, the higher span readers increase the amount of thematic processing, perhaps with the goal of using relational thematic processing to improve retention of detail information.

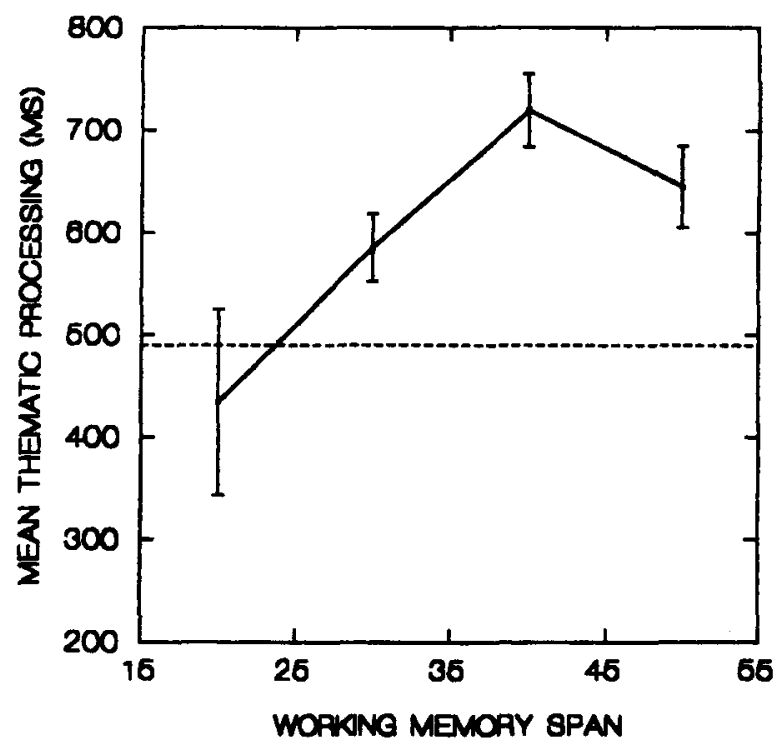

Figure 9. Relation between thematic processing and working memory span in Experiment 3.

\section{Answers to Multiple-Choice Questions}

If the conclusion is correct that higher span readers are using relational thematic processing to aid retention of details, then the reading time data suggest that there should be a corresponding general increase in question answering performance as the level of WM span increases. That is, performance on both topic and detail questions should increase as the level of WM span increases. The relevant data are shown in Figure 10. Consistent with our interpretation of the reading time data, performance on both topic questions $[F(1,118)=20.48$, $\left.M S_{\mathrm{e}}=.010\right]$ and detail questions $[F(1,118)=14.42$, $\left.M S_{\mathrm{e}}=.016\right]$ increased with WM span.

\section{GENERAL DISCUSSION}

The purpose of the present study was to extend previous research by examining whether quantitative differences in WM span affect the comprehension processes that readers use to process simple expository text. Other researchers using narrative text have obtained data consistent with this hypothesis (Just \& Carpenter, 1992; Perfetti, 1985; Lee-Sammons \& Whitney, 1991; Whitney et al., 1991). The data from these experiments are in agreement with the general finding that performance differences among readers with different WM spans are often small or negligible when the materials are easy, but larger when the task of comprehension is made more difficult (Just \& Carpenter, 1992; Raney, 1993). In the topic-present condition of Experiment 2, when the experimental materials were easier to process, high- and low-span subjects used similar WM management strategies, which resulted in similar accuracy for both topic and detail information. However, when thematic process- 


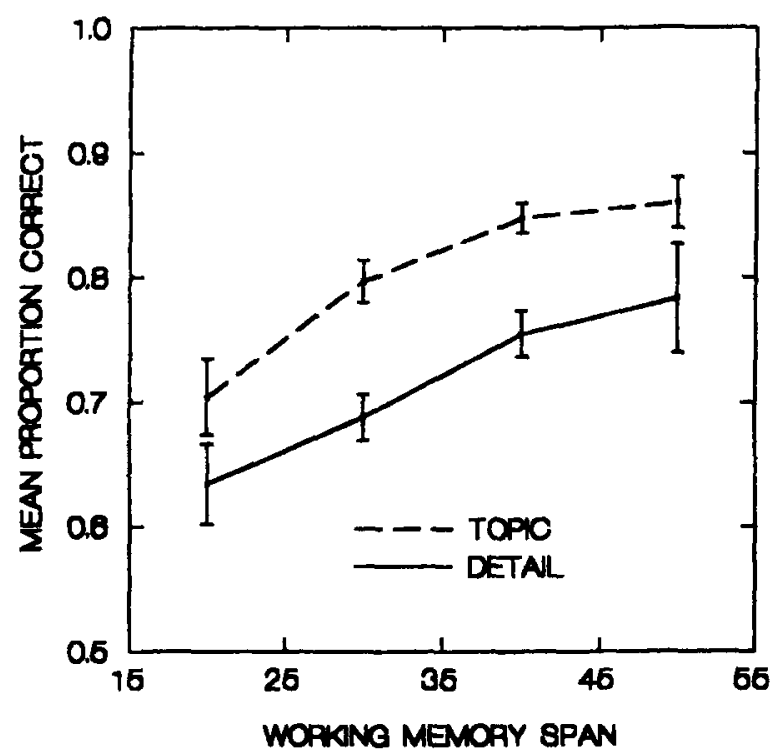

Figure 10. Performance on topic and detail comprehension questions as a function of working memory span in Experiment 3.

ing became more difficult, as for example, in the topicabsent condition of Experiment 2, performance differences became more apparent. This interaction between WM span and task difficulty lends support to the common theoretical assumption that WM plays a central role in the coordination and management of information processing in comprehension (e.g., Just \& Carpenter, 1992; Kintsch, 1988; Sanford \& Garrod, 1981).

More specifically, we found that across the range of WM span, readers construct and maintain thematic information in WM. This finding is inconsistent with theories that claim that readers only maintain local coherence relations (McKoon \& Ratcliff, 1992) but consistent with the hypothesis that in at least some reading contexts, readers attempt to maintain some thematic propositions in WM in order to maintain global coherence at the passage level (Kintsch, 1993; Trabasso \& Suh, 1993; Whitney et al., 1991). Perhaps more importantly, the present data show that such global coherence processes, or what we have called here "relational thematic processing," can improve retention of the details of a text, as shown by the data from Experiment 3 (see also McDaniel, Einstein, Dunay, \& Cobb, 1986). However, the present results also show that not all thematic processing improves retention of detail information. Thematic processing was greater in the topic-absent condition than in the topic-present condition of Experiment 2. This was true across the range of WM span. However, there was no concomitant increase in performance on detail questions in Experiment 2 to mirror the increase in performance by higher span subjects who performed extensive thematic processing in Experiment 3. The likely explanation for these effects is that the increase in thematic processing observed in the topic-absent condition of Experiment 2 was due to the increased difficulty of constructing the thematic proposition. Thus, in the topicabsent condition, there was no increase in relational thematic processing above that found in the topic-present condition, so retention of details was not improved; in fact, performance on detail questions declined somewhat for low-span subjects. For low-span subjects, the difficulty of performing two kinds of item-specific processes at once (constructing a thematic proposition while comprehending a specific detail) resulted in a kind of tradeoff in WM in which comprehension of details suffered.

That we obtained individual differences in WM management and performance on comprehension questions by using texts that were relatively short and simple in structure has implications for an educational system in which the reading materials are usually longer, more complex, and more variable in organization than the texts used in these experiments. Consider the research on advanced organizers. Many investigators have tried to improve comprehension of text by providing advanced information on text organization as a way of improving what is learned from text (e.g., Reder, 1985). Studies on advanced organizers have produced a confusing, and sometimes conflicting, pattern of results. Although information about text organization can facilitate thematic processing (Mayer, 1979; Reder, 1985), there is disagreement over who is aided by such manipulations. Some investigators have reported more facilitation for poor readers (e.g., Mayer, 1980), while others have reported the opposite (e.g., Derry, 1984).

The claim that advanced organizers help poor readers more than they help good readers suggests that poor readers do not spontaneously perform thematic processing (see, e.g., Meyer, 1975), or at least do not perform it as effectively as good readers (e.g., Lorch, Lorch, \& Mogan, 1987). However, WM span correlates highly with reading achievement (e.g., Turner \& Engle, 1989), and we found that in some conditions low WM span readers performed thematic processing, even if it was at the expense of retaining detail information. In addition, roughly the same level of thematic processing was observed among lower span readers across Experiments 2 and 3 , even though in the latter experiment the subjects had no reason to expect that any topic questions would be asked. Of course, there could be many reasons for the conflicting results. For one, it is difficult to evaluate claims about the effects of procedures on "poor readers" in general. Kloster and Winne (1989) noted that the direction of many aptitude $\times$ treatment interactions in reading varies as a function of how aptitude is defined. So, what is true of poor readers who have low WM capacity may not be true of other groups of poor readers. In addition, the efficiency with which readers can use a WM management strategy and the particular strategy that readers use may vary as a function of the difficulty of the text and the reading goals employed (cf. Lorch et al., 1987; Mannes \& Kintsch, 1987).

Just how flexible readers are in adapting to context is not well understood. Some studies suggest that proficient readers are more likely than less proficient readers 
to alter their strategies to accommodate different types of materials and tasks (Just \& Carpenter, 1992; Lorch et al., 1987). This was demonstrated clearly in the present study by the higher span subjects who read the passages quite differently in Experiments 2 and 3, depending on the type of comprehension questions that were expected. However, other studies suggest that low-span readers sometimes compensate for their lower capacity by making appropriate adjustments to task demands (Lee-Sammons \& Whitney, 1991; Whitney et al., 1991). More research needs to be done to determine how individual differences and variations in criterial tasks and materials affect the WM management strategies used in comprehension. We believe that the general approach taken here holds considerable promise for elucidating individual differences in adjustment to contextual conditions. That is, by identifying those contexts in which, for example, higher and lower span subjects do not seem to differ (as in Experiment 1 and the topic-present condition of Experiment 2) and by systematically varying conditions until span differences are obtained, we may be able to identify the factors that induce readers to adopt particular strategies.

\section{REFERENCES}

BadDeley, A. D. (1986). Working memory. New York: Oxford University Press.

Baddeley, A. D., Logie, R., Nimmo-Smith, I., \& Brereton, N. (1985). Components of fluent reading. Journal of Memory \& Language, 24, 119-131.

BLACK, J. (1985). An exposition on understanding expository text. In B. K. Britton \& J. Black (Eds.), Understanding expository text (pp. 250-265). Hillsdale, NJ: Erlbaum.

Britron, B. K., GlynN, S. M., \& Smith, J. W. (1985). Cognitive demands of processing expository text: A cognitive workbench model. In B. K. Britton \& J. B. Black (Eds.), Understanding expository text (pp. 227-248). Hillsdale, NJ: Erlbaum.

Cronbach, L. J., \& Snow, R. E. (1977). Aptitudes and instructional methods: A handbook for research on interactions. New York: Halsted Press.

DANeman, M., \& CARpenter. P. (1980). Individual differences in working memory and reading. Journal of Verbal Learning \& Verbal Behavior, 19, 450-466

DERRY, S. J. (1984). Effects of an organizer on memory for prose. Journal of Educational Psychology, 76, 98-107.

Einstein, G. O., McDaniel, M. A., Owen, P. D., \& Cote, N. C. (1990). Encoding and recall of texts: The importance of material appropriate processing. Journal of Memory \& Language, 29, 566-581.

Engle, R. W., Cantor, J., \& Carullo, J. J. (1992). Individual differences in working memory and comprehension: A test of four hypotheses. Journal of Experimenal Psychology: Learning, Memory. \& Cognition, 18, 972-992.

Epstein, W., Gi.enberG, A. M., \& Bradley, M. M. (1984). Coactivation and comprehension: Contribution of text variables to the illusion of knowing. Memory \& Cognition, 12, 355-360.

Fischer, B., \& GlanZer, M. (1986). Short-term storage and the processing of cohesion during reading. Quarterly Journal of Experimental Psychology, 38A, 431-460.

Fi.ercher, C. (1986). Strategies for allocation of short-term memory during comprehension. Journal of Memory \& Language, 25, 43-58.

Fodor, J. A. (1983). The modularity of mind. Cambridge, MA: MIT Press, Bradford Books.

Glanzer. M., \& Nolan. S. (1986). Memory mechanisms in text comprehension. In G. H. Bower (Ed.), The psychology of learning and motivation: Advances in research and theory (Vol. 20, pp. 275-317). Orlando, FL: Academic Press.
HaberLandt, K. F. (1984). Components of sentence and word reading times. In D. Kieras \& M. Just (Eds.), New methods in comprehension research (pp. 219-251). Hillsdale, NJ: Erlbaum.

Haberlandt, K. F., \& Graesser, A. C. (1985). Component processes in text comprehension and some of their interactions. Journal of Experimental Psychology: General, 114, 357-374.

Hare, V. C., Rabinowitz, M., \& Schieble, K. M. (1989). Text effects on main idea comprehension. Reading Research Quarterly, 24, 72-88.

JOHNSON-LAIRD, P. N. (1983). Mental models: Towards a cognitive science of language, inference, and consciousness. Cambridge, MA: Harvard University Press.

JUST, M. A., \& CARPENTER, P. A. (1987). The psychology of reading and language comprehension. Newton, MA: Allyn \& Bacon.

Just, M. A., \& Carpenter, P. A. (1992). A capacity theory of comprehension: Individual differences in working memory. Psychological Review, 99, 122-149.

KIERAS, D. E. (1981a). Component processes in the comprehension of simple prose. Journal of Verbal Learning \& Verbal Behavior, 20 , $1-23$.

KIERAS, D. E. ( 1981 b). Topicalization effects in cued recall of technical prose. Memory \& Cognition, 9, 541-549.

KIERAS, D. E. (1982). A model of reader strategy for abstracting main ideas from simple technical prose. Text, 2, 47-81.

KIERAS, D. E. (1984). A method for comparing a simulation to reading time data. In D. E. Kieras \& M. A. Just (Eds.), New methods in comprehension research (pp. 299-325). Hillsdale, NJ: Erlbaum.

KIERAS, D. E. (1985). Thematic processes in the comprehension of technical prose. In B. K. Britton \& J. B. Black (Eds), Understanding expository text (pp. 89-105). Hillsdale, NJ: Erlbaum.

KINTSCH, W. (1988). The role of knowledge in discourse comprehension: A construction-integration model. Psychological Review, 95, 163-182.

KINTSCH, W. (1993). Information accretion and reduction in text processing: Inferences. Discourse Processes, 16, 193-202.

Kintsch, W., Britton, B. K., Fletcher, C. R., Kintsch, E., Mannes, S. M., \& NaTHAN, M. J. (1993), A comprehension-based approach to learning and understanding. In D. L. Medin (Ed.), The psychology of learning and motivation: Advances in research and theory (Vol. 30, pp. 165-211). San Diego, CA: Academic Press.

KinTsCh, W., \& VAN DiJk, T. A. (1978). Toward a model of text comprehension and production. Psychological Review, 85, 363-393.

KLOSTER, A. M., \& WINNE, P. H. (1989). The effects of different types of organizers on students' learning from text. Journal of Educational Psychology, 81, 9-15.

LeE-SAMmONS, W., \& Whitney, P. (1991). Reading perspectives and memory for text: An individual differences analysis. Journal of Experimental Psychology: Learning, Memory, \& Cognition, 17, 10741081

LOMAN, N. L., \& MaYer, R. E. (1983). Signaling techniques that increase the understandability of expository prose. Journal of Educational Psychology, 75, 402-412.

LoRCh, R., LoRCh, E., \& Matthews, P. (1985). On-line processing of the topic structure of a text. Journal of Memory \& Language, 24, 350-362.

Lorch, R., Lorch, E., \& Mogan, A. (1987). Task effects and individual difference in on-line processing of a text. Discourse Processes, 10,63-80.

MacDonald, M. C., Just, M. A., \& Carpenter, P. A. (1992). Working memory constraints on the processing of syntactic ambiguity. Cognitive Psychology, 24, 56-98.

ManNES, S., \& KinTSCH, W. (1987). Knowledge organization and text organization. Cognition \& Instruction, 4, 91-115.

MarShall, N., \& Glock, M. D. (1979). Comprehension of connected discourse: A study into the relationships between the structure of text and information recalled. Reading Research Quarterly, 14, 10 56.

MAYER, R. E. (1979). Can advance organizers influence meaningful learning? Review of Education Research, 49, 371-383.

MAYER, R. E. (1980). Elaboration techniques that increase the meaningfulness of technical text. Journal of Educational Psychology, 72, 770-784

McDaniel, M. A., Einstein, G. O., Dunay, P. K., \& Cobb, R. E. 
(1986). Encoding difficulty and memory: Toward a unifying theory. Journal of Memory \& Language, 25, 645-656.

McKoOn, G., \& Ratcliff, R. (1992). Inference during reading. Psychological Review, 99, 440-466.

MEYER, B. J. F. (1975). The organization of prose and its effects on memory. Amsterdam: Elsevier, North-Holland.

Meyer, B. J. F., Brandt, D. M., \& Bluth, G. J. (1980). Use of toplevel structure in text: Key for reading comprehension of ninthgrade students. Reading Research Quarterly, 16, 72-103.

MEYER, B. J. F., \& RiCE, E. (1982). The interaction of reader strategies and the organization of text. Text, 2, 155-192.

Olson, G. M., MaCK, R. L., \& DufFy, S. A. (1981). Cognitive aspects of genre. Poetics, 10, 283-315.

PedhazUR, E. J. (1982). Multiple regression in behavioral research. New York: Harcourt Brace Jovanovich.

Perfetti, C. A. (1985). Reading ability. New York: Oxford University Press.

PerfetTI, C. A. (1989). There are generalized abilities and one of them is reading. In L. B. Resnick (Ed.), Knowing, learning and instruction: Essays in honor of Robert Glaser (pp. 307-335). Hillsdale, NJ: Erlbaum.

RANEY, G. (1993). Monitoring changes in cognitive load during reading: An event-related brain potential and reaction time analysis. Journal of Experimental Psychology: Learning, Memory, \& Cognition, 19, 51-69.

REDER, L. M. (1985). Techniques available to author, teacher, and reader to improve retention of the main ideas of a chapter. In S. F.
Chipman, J. W. Segal, \& J. R. Glaser (Eds.), Thinking and learning skills: Vol. 2. Research and open questions (pp. 37-63). Hillsdale, $\mathrm{NJ}$ : Erlbaum.

REDER, L. M., \& ANDERSon, J. R. (1980). A comparison of texts and their summaries: Memorial consequences. Journal of Verbal Learning \& Verbal Behavior, 19, 121-134.

Risko, V. J., \& Alvarez, M. C. (1986). An investigation of poor readers' use of a thematic strategy to comprehend text. Reading Research Quarterly, 21, 298-315.

SANFORD, A. J., \& GARROD, S. C. (1981). Understanding written language. New York: Wiley.

SMITH, E. E., \& SwINNEY, D. A. (1992). The role of schemas in reading text: A real-time examination. Discourse Processes, 15, 303316.

Trabasso, T., \& SuH, S. (1993). Understanding text: Achieving explanatory coherence through on-line inferences and mental operations in working memory. Discourse Processes, 16, 3-34.

TURNER, M. L., \& ENGLE, R. W. (1989). Is working memory task dependent? Journal of Memory \& Language, 28, 127-154.

vaN DiJK, T., \& KinTsCH, W. (1983). Strategies of discourse comprehension. New York: Academic Press.

Whitney, P., RitChiE, B., \& CLARK, M. (1991). Working memory and the use of elaborative inferences in text comprehension. Discourse Processes, 14, 133-145.

(Manuscript received July 28, 1994; revision accepted for publication December 30, 1994.) 